\title{
Effective factor on catalysis of Niobium oxide for Magnesium
}

Hiroyuki Gi ${ }^{a}$, Keita Shinzato ${ }^{b}$, Ratna Balgis $^{b}$, Takashi Ogi ${ }^{a}$, Masahiro Sadakane $^{a}$, Yongming Wang ${ }^{c}$,

Shigehito Isobe $e^{d}$ Hiroki Miyaoka ${ }^{a, e^{*}}$, Takayuki Ichikawa ${ }^{a, b, e}$

aGraduate School of Advanced Science and Engineering, Hiroshima University, 1-4-1

Kagamiyama, Higashi-Hiroshima, 739-8527, Japan

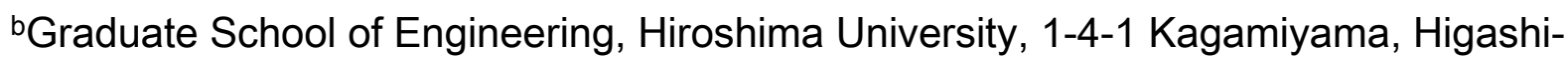

Hiroshima, 739-8527, Japan

${ }^{c}$ Creative Research Institution, Hokkaido University, N-21, W-10, Sapporo 001-0021, Japan

dGraduate School of Engineering, Hokkaido University, N-13, W-8, Sapporo 060-8628,

Japan

eNatural Science Center for Basic Research and Development, Hiroshima University, 1-3-1

Kagamiyama, Higashi-Hiroshima, 739-8530, Japan

corresponding author: Hiroki Miyaoka (miyaoka@hiroshima-u.ac.jp)

Figure S1. Schematic image of spray pyrolysis apparatus

Figure S2. XRD pattens of grease and polyimide sheet as background 
Figure S3. TG-DTA of $\mathrm{NH}_{4}\left[\mathrm{NbO}\left(\mathrm{C}_{2} \mathrm{O}_{4}\right)_{2}\left(\mathrm{H}_{2} \mathrm{O}\right)_{2}\right]-10.5 \mathrm{H}_{2} \mathrm{O}$ under air flow.

Figure S4. X-ray diffraction patterns of (a) $\mathrm{NH}_{4}\left[\mathrm{NbO}\left(\mathrm{C}_{2} \mathrm{O}_{4}\right)_{2}\left(\mathrm{H}_{2} \mathrm{O}\right)_{2}\right]-10.5 \mathrm{H}_{2} \mathrm{O}$, and solid after calcination of $\mathrm{NH}_{4}\left[\mathrm{NbO}\left(\mathrm{C}_{2} \mathrm{O}_{4}\right)_{2}\left(\mathrm{H}_{2} \mathrm{O}\right)_{2}\right]-10.5 \mathrm{H}_{2} \mathrm{O}$ at (b) 300 , (c) 500 , (d) 600 , and (e) $700{ }^{\circ} \mathrm{C}$.

Figure S5. Size distribution of $\mathrm{Nb}_{2} \mathrm{O}_{5}$ prepared by spray pyrolysis method at (a) 500 and (b) $1000{ }^{\circ} \mathrm{C}$.

Figure S6. TEM image of $\mathrm{Nb}_{2} \mathrm{O}_{5}$ synthesized by spray pyrolysis at $500{ }^{\circ} \mathrm{C}$ : (a) spherical shell-like particle, (b) enlarged image of area shown by squire in (a), (c) spherical ball-like particle

Figure S7. TEM image of $\mathrm{Nb}_{2} \mathrm{O}_{5}$ synthesized by spray pyrolysis at $1000{ }^{\circ} \mathrm{C}$ : (a) polyhedron particle, (b) enlarged image of area shown by squire in (a), (c) other polyhedron particle, (d) and (e) enlarged images of area shown by squire 1 and 2 in (c), respectively.

Figure S8. XRD patterns of the as-milled $\mathrm{MgH}_{2}$ with each $\mathrm{Nb}_{2} \mathrm{O}_{5}$

Figure S9. XRD patterns of the $\mathrm{MgH}_{2}$ with each $\mathrm{Nb}_{2} \mathrm{O}_{5}$ after TG measurements

Figure S10. XRD patterns of the $\mathrm{MgH}_{2}$ with each $\mathrm{Nb}_{2} \mathrm{O}_{5}$ after $\mathrm{H}_{2}$ absorption experiments 


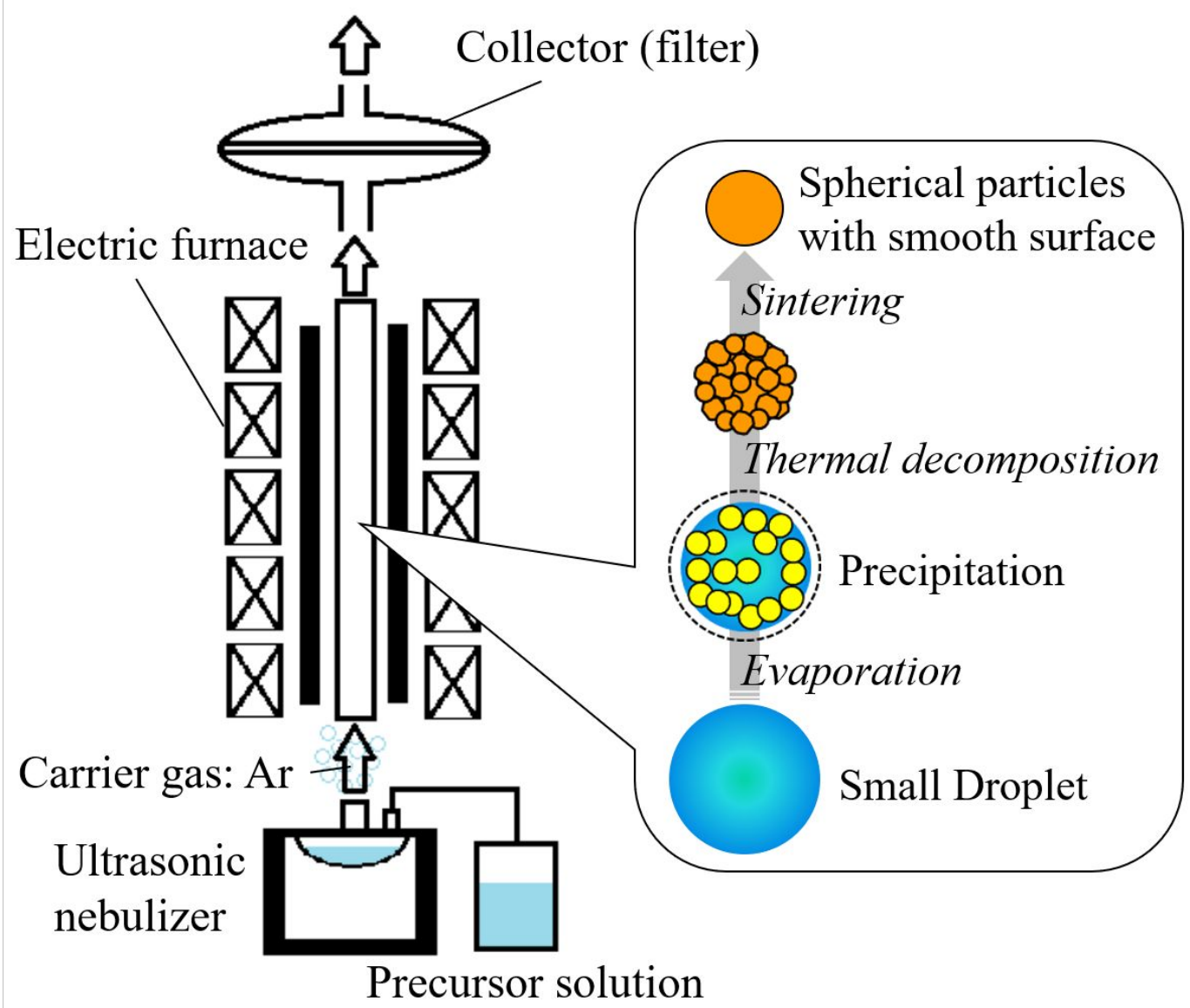

Figure S1. Schematic image of spray pyrolysis apparatus 


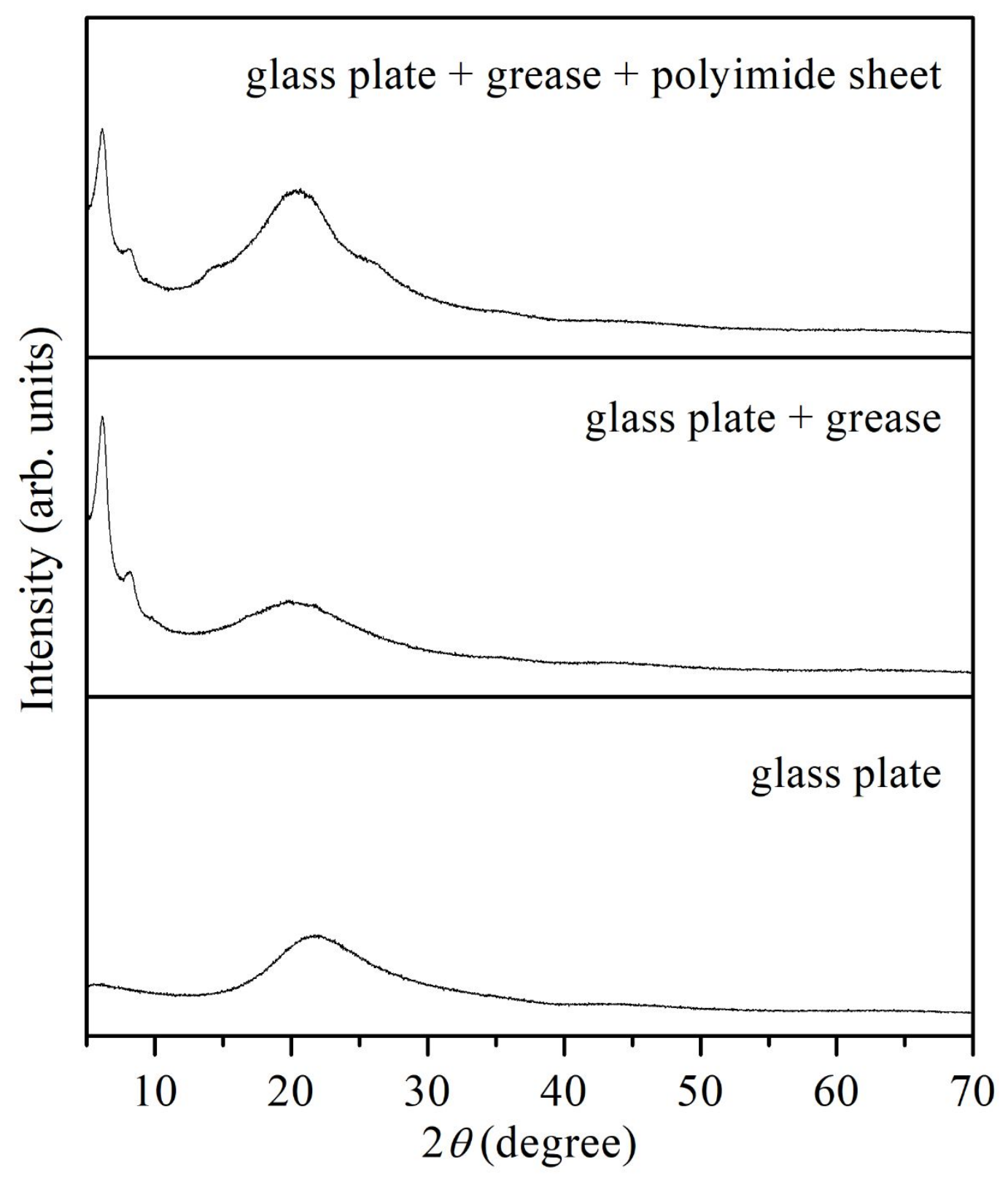

Figure S2. XRD pattens of grease and polyimide sheet as background 
Thermogravimetry-differential thermal analysis (TG-DTA) of $\mathrm{NH}_{4}\left[\mathrm{NbO}\left(\mathrm{C}_{2} \mathrm{O}_{4}\right)_{2}\left(\mathrm{H}_{2} \mathrm{O}\right)_{2}\right]-10.5 \mathrm{H}_{2} \mathrm{O}$ was performed by using a TG/DTA7300 instrument (SII, Japan) at a heating rate of $10{ }^{\circ} \mathrm{C} / \mathrm{min}$ under air flow $(50 \mathrm{~mL} / \mathrm{s})$. XRD patterns of the solid products pared by simple calcination method were collected using a powder X-ray diffractometer (Bulker D2 PHASER) with a $\mathrm{Cu} \mathrm{K \alpha} \mathrm{X-ray} \mathrm{source} \mathrm{and} \mathrm{a} \mathrm{Ni} \mathrm{filter}$ at $30 \mathrm{kV}$ and $10 \mathrm{~mA}$.

The TG-DTA of $\mathrm{NH}_{4}\left[\mathrm{NbO}\left(\mathrm{C}_{2} \mathrm{O}_{4}\right)_{2}\left(\mathrm{H}_{2} \mathrm{O}\right)_{2}\right]-10.5 \mathrm{H}_{2} \mathrm{O}$ under air flow shows endothermic weight loss between ca. 100 and $300{ }^{\circ} \mathrm{C}$, and exothermic weight loss at about $580{ }^{\circ} \mathrm{C}$ as shown in Fig. S3. The total weight loss of about $75 \%$ up to $600{ }^{\circ} \mathrm{C}$ corresponding to the formation of $\mathrm{Nb}_{2} \mathrm{O}_{5}$, because the theoretical weight loss from $\mathrm{NH}_{4}\left[\mathrm{NbO}\left(\mathrm{C}_{2} \mathrm{O}_{4}\right)_{2}\left(\mathrm{H}_{2} \mathrm{O}\right)_{2}\right]-10.5 \mathrm{H}_{2} \mathrm{O}$ to $1 / 2 \mathrm{Nb}_{2} \mathrm{O}_{5}$ is $75 \%$. Presence of crystalline $\mathrm{Nb}_{2} \mathrm{O}_{5}$ after heating at $600{ }^{\circ} \mathrm{C}$ was confirmed by XRD (See Figure $\mathrm{S} 4(\mathrm{~d})$ ), while solids obtained after heating less than $500{ }^{\circ} \mathrm{C}$ were amorphous (See Figure S3 (b) and (c)). The weight loss at about $580{ }^{\circ} \mathrm{C}$ is $3 \%$ which indicate that formula of the amorphous $\mathrm{Nb}$ oxide is $\mathrm{Nb}_{2} \mathrm{O}_{5}-2 \mathrm{H}_{2} \mathrm{O}$.

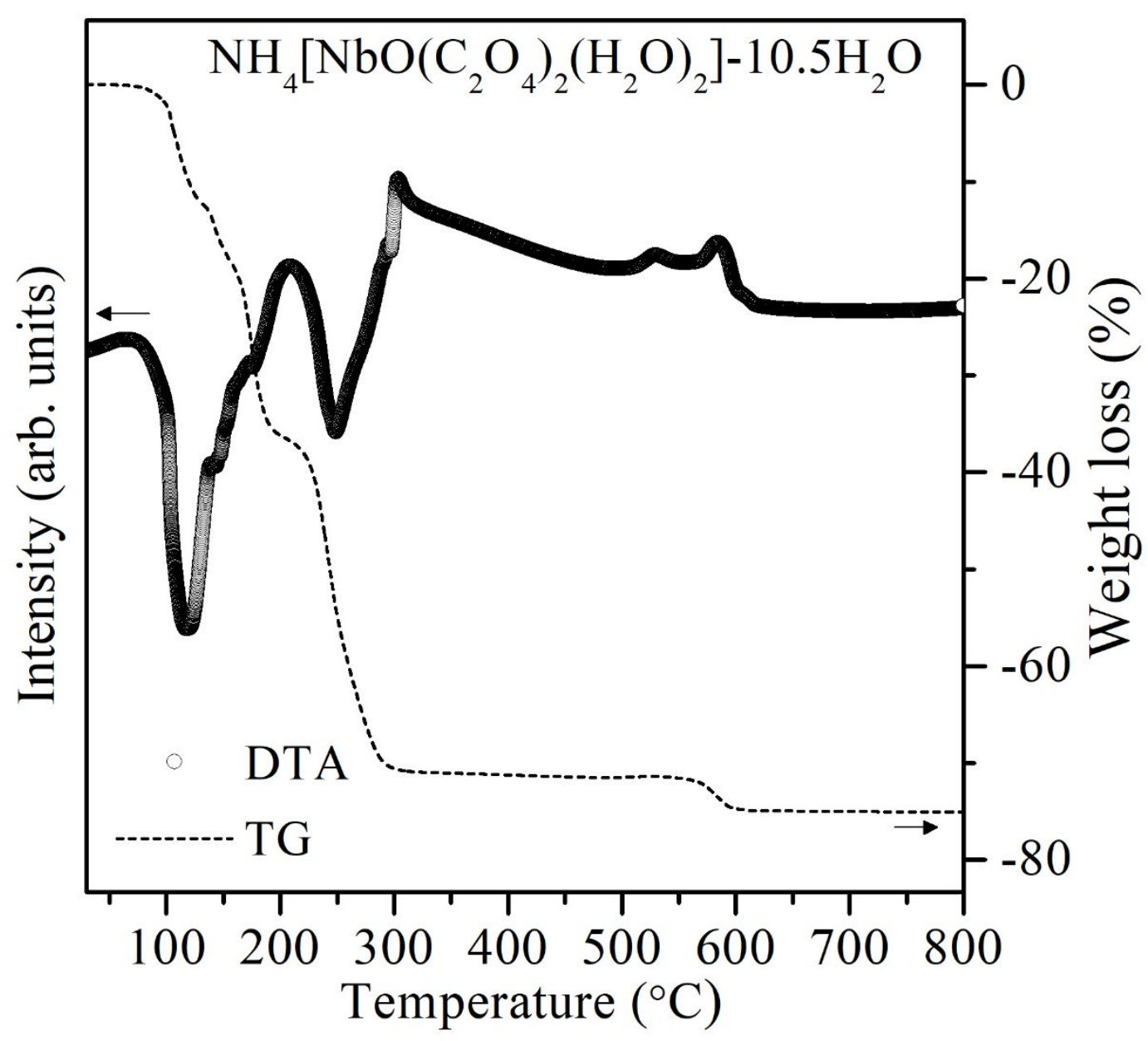

Figure S3. TG-DTA of $\mathrm{NH}_{4}\left[\mathrm{NbO}\left(\mathrm{C}_{2} \mathrm{O}_{4}\right)_{2}\left(\mathrm{H}_{2} \mathrm{O}\right)_{2}\right]-10.5 \mathrm{H}_{2} \mathrm{O}$ under air flow. 


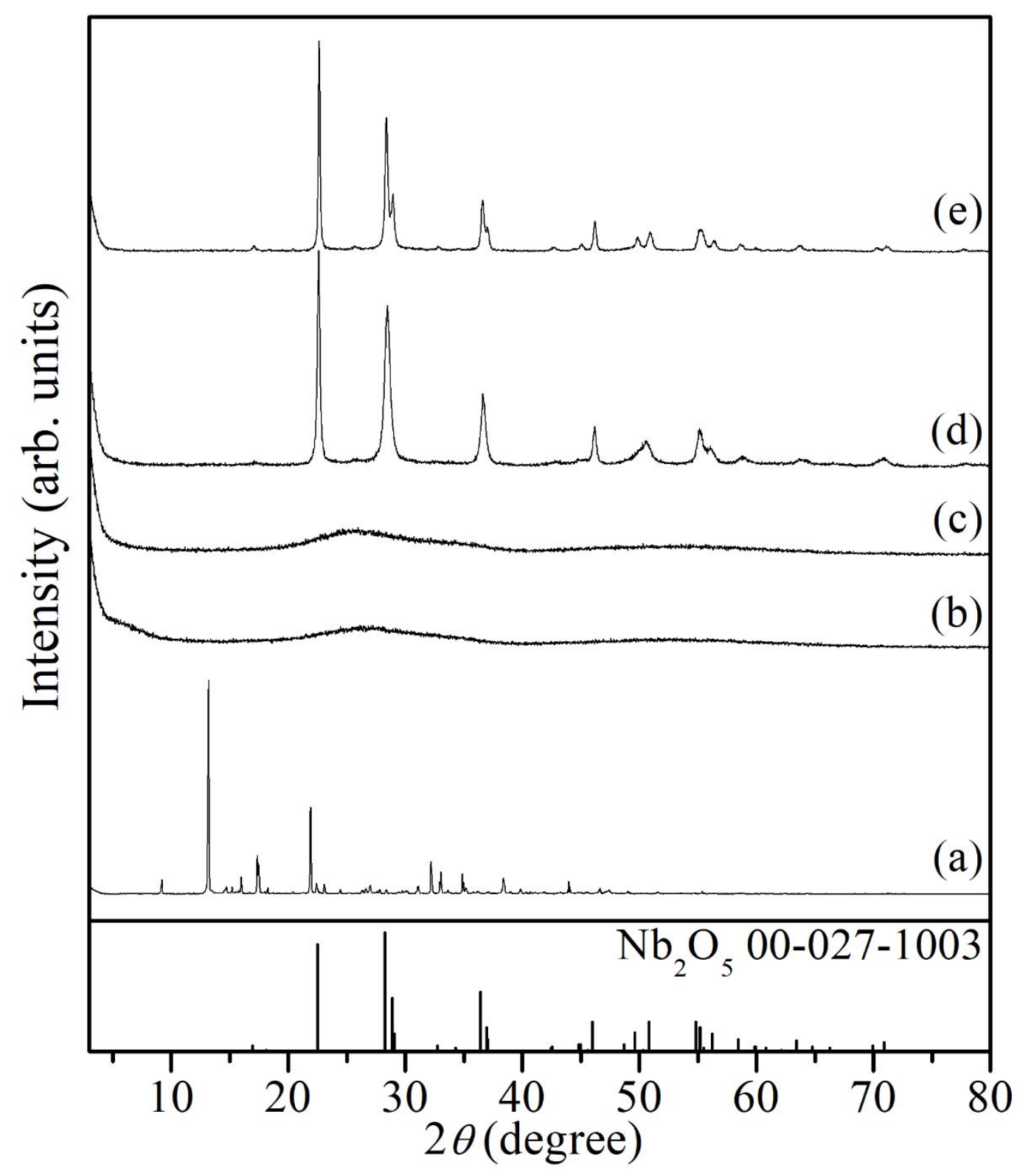

Figure S4. X-ray diffraction patterns of (a) $\mathrm{NH}_{4}\left[\mathrm{NbO}\left(\mathrm{C}_{2} \mathrm{O}_{4}\right)_{2}\left(\mathrm{H}_{2} \mathrm{O}\right)_{2}\right]-10.5 \mathrm{H}_{2} \mathrm{O}$, and solid after calcination of $\mathrm{NH}_{4}\left[\mathrm{NbO}\left(\mathrm{C}_{2} \mathrm{O}_{4}\right)_{2}\left(\mathrm{H}_{2} \mathrm{O}\right)_{2}\right]-10.5 \mathrm{H}_{2} \mathrm{O}$ at (b) 300 , (c) 500 , (d) 600 , and (e) $700{ }^{\circ} \mathrm{C}$. 
(a)

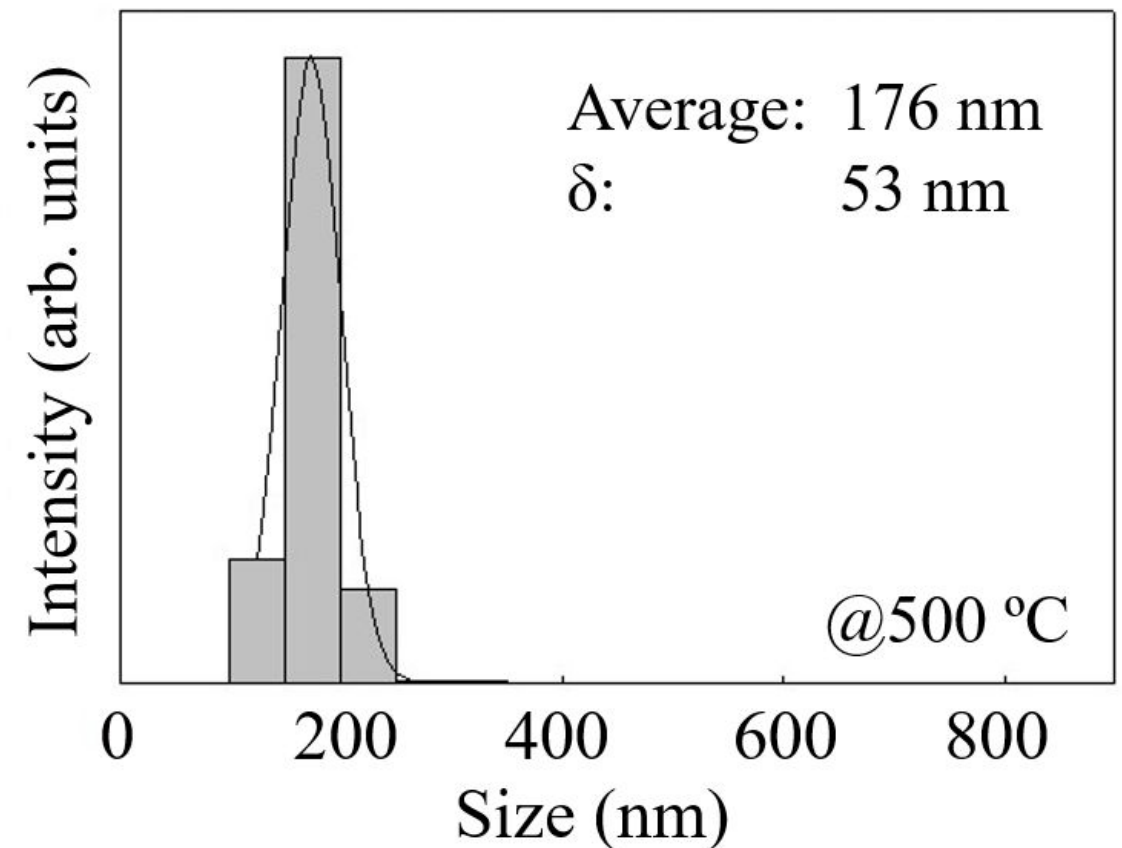

(b)

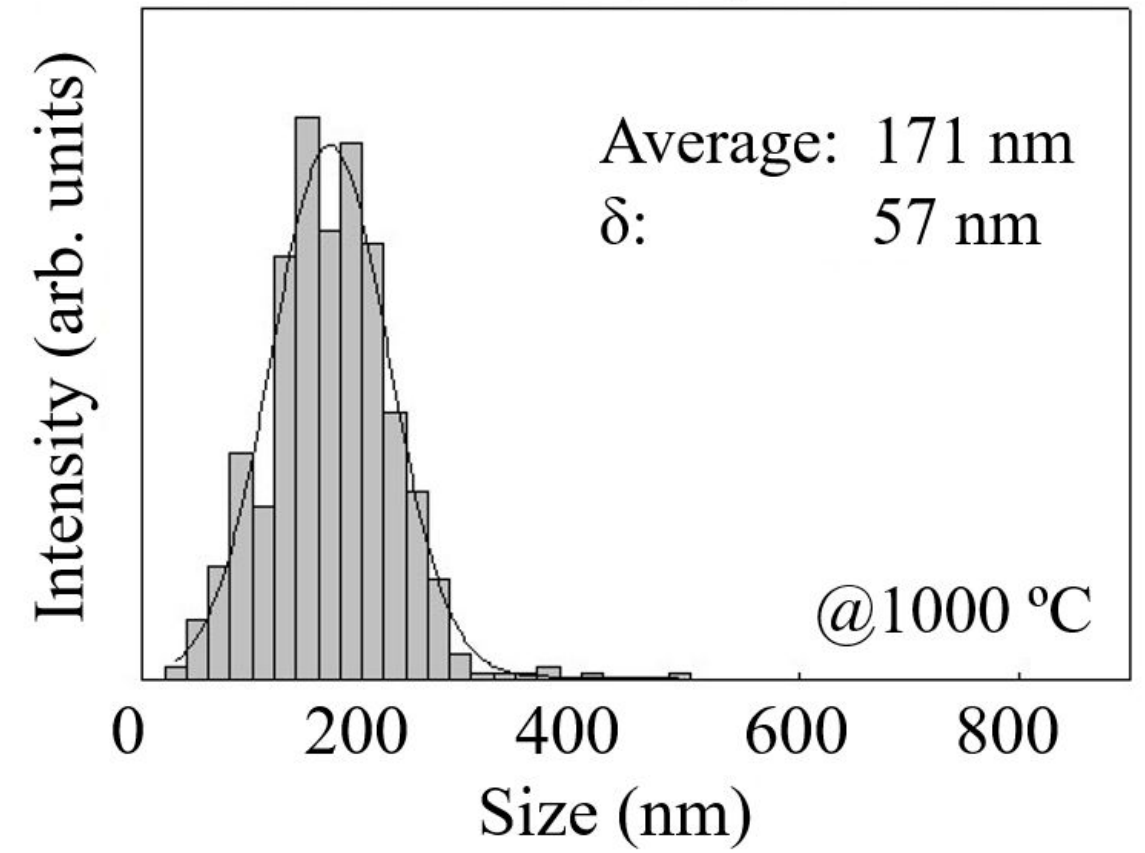

Figure S5. Size distribution of $\mathrm{Nb}_{2} \mathrm{O}_{5}$ prepared by spray pyrolysis method at (a) 500 and (b) $1000{ }^{\circ} \mathrm{C}$. 

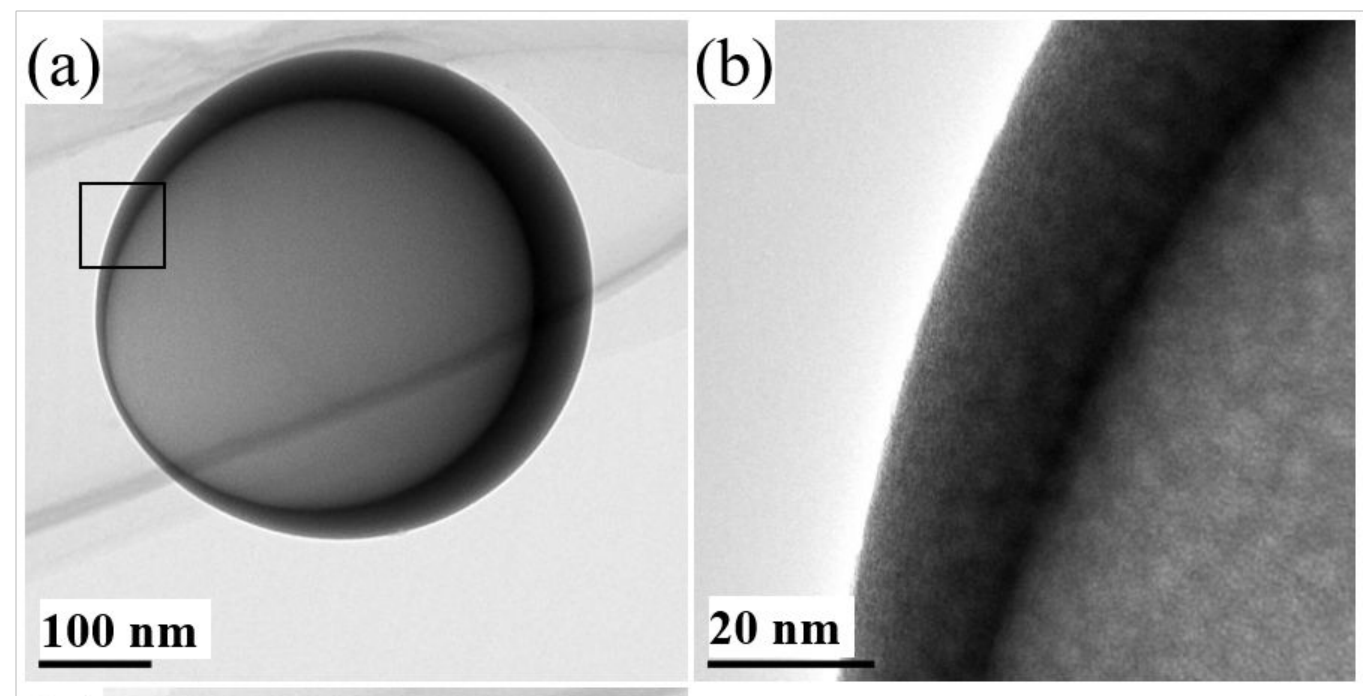

(c)

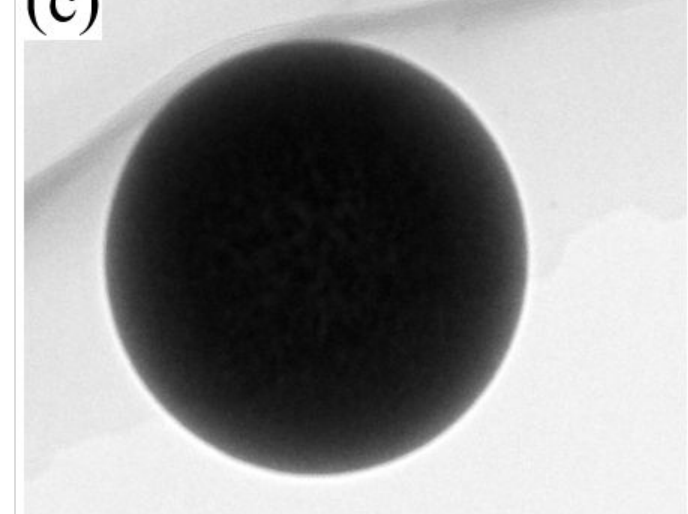

\section{$100 \mathrm{~nm}$}

Figure S6. TEM image of $\mathrm{Nb}_{2} \mathrm{O}_{5}$ synthesized by spray pyrolysis at $500{ }^{\circ} \mathrm{C}$ : (a) spherical shell-like particle, (b) enlarged image of area shown by squire in (a), (c) spherical ball-like particle 

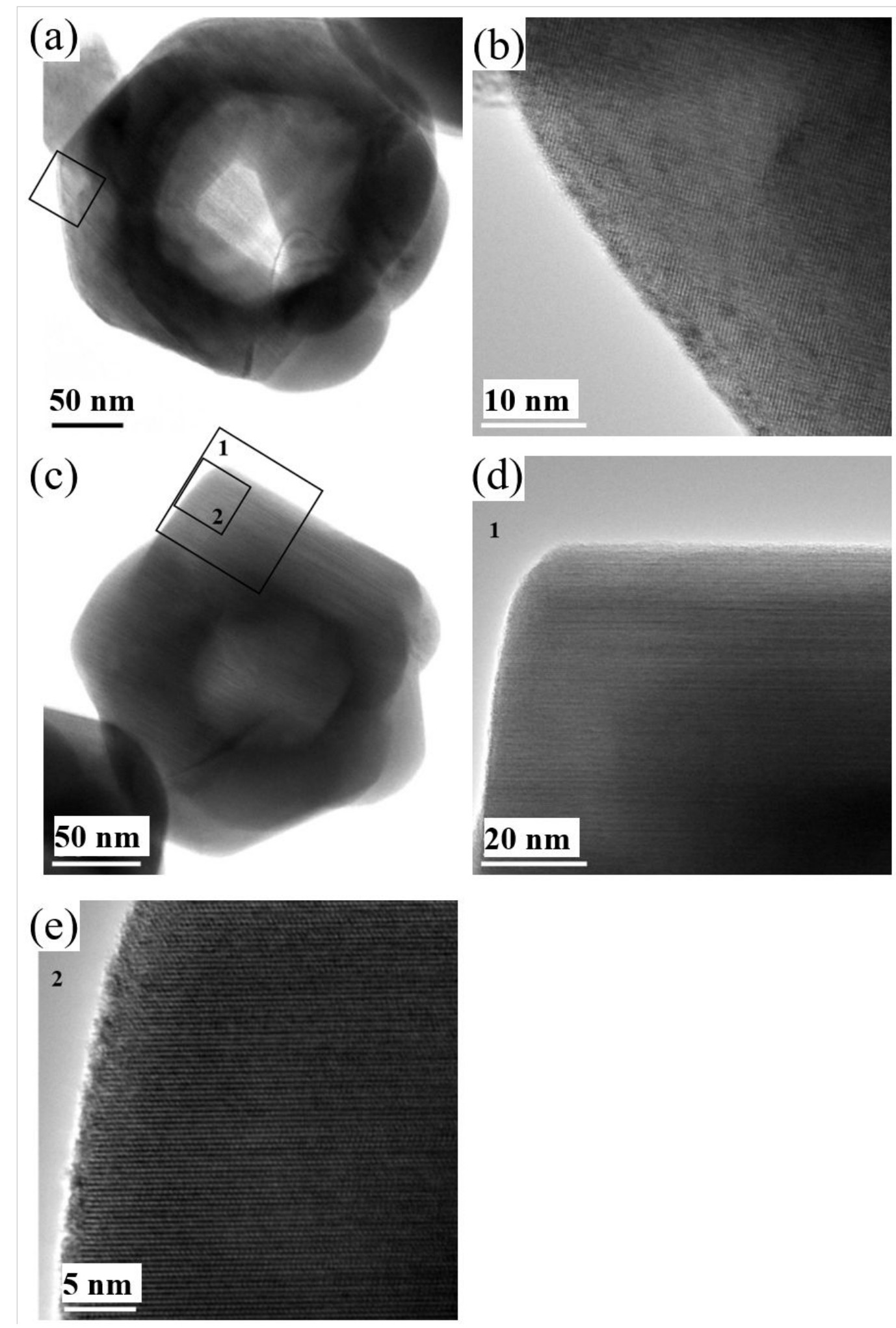

Figure $\mathbf{S 7}$. TEM image of $\mathrm{Nb}_{2} \mathrm{O}_{5}$ synthesized by spray pyrolysis at $1000^{\circ} \mathrm{C}$ : (a) polyhedron particle, (b) enlarged image of area shown by squire in (a), (c) other polyhedron particle, (d) and (e) enlarged images of area shown by squire 1 and 2 in (c), respectively. 


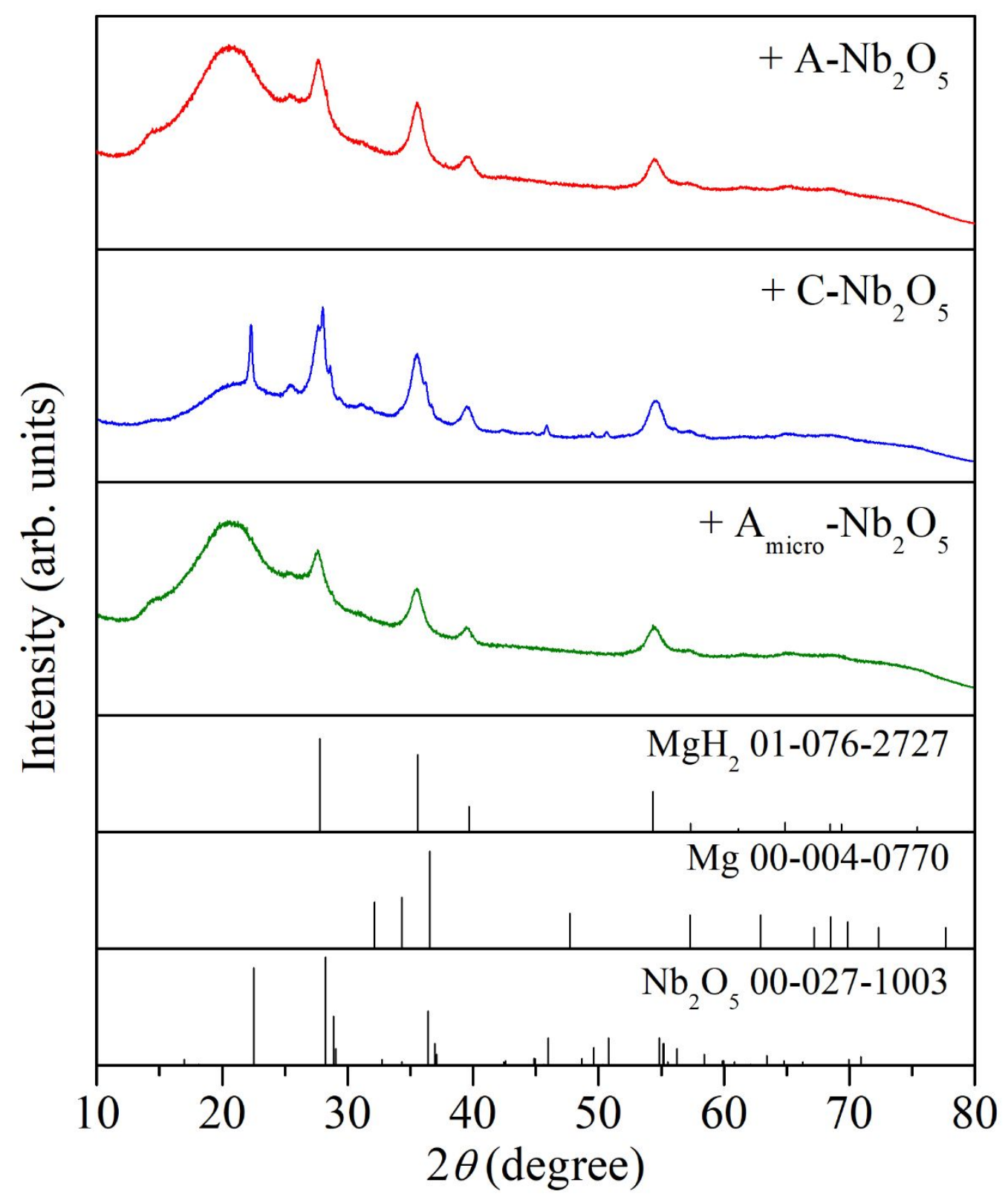

Figure S8. XRD patterns of the as-milled $\mathrm{MgH}_{2}$ with each $\mathrm{Nb}_{2} \mathrm{O}_{5}$ 


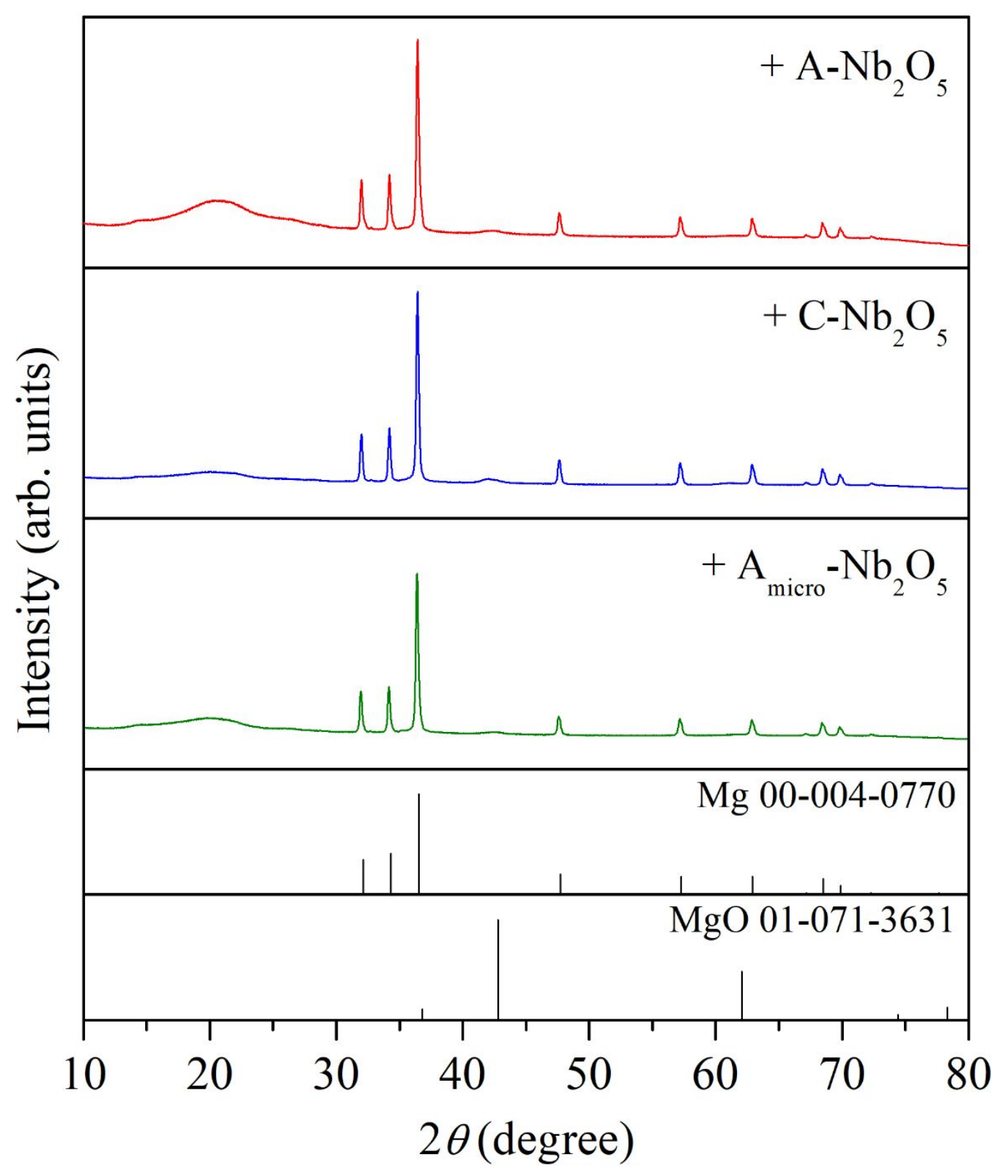

Figure S9. XRD patterns of the $\mathrm{MgH}_{2}$ with each $\mathrm{Nb}_{2} \mathrm{O}_{5}$ after TG measurements 


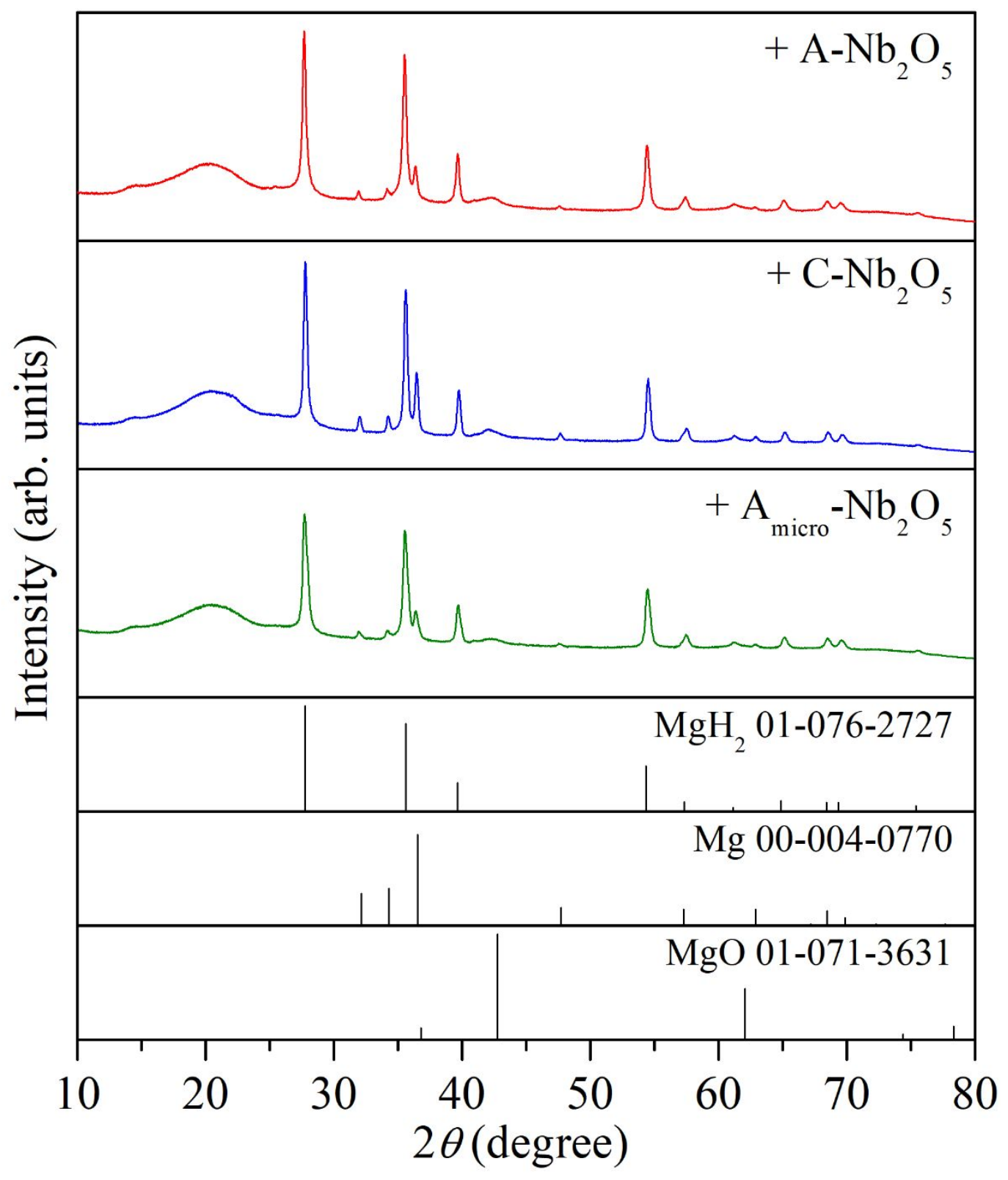

Figure S10. XRD patterns of the $\mathrm{MgH}_{2}$ with each $\mathrm{Nb}_{2} \mathrm{O}_{5}$ after $\mathrm{H}_{2}$ absorption experiments 